\title{
Paradoxical embolism: a rare life- and limb-threatening emergency
}

\author{
Christine E. Tang, MD CM
}

\begin{abstract}
This article presents a case of a 43-year-old man with paradoxical embolism. The patient had simultaneous deep venous thrombosis, pulmonary embolism and bilateral limb-threatening arterial occlusions. The unifying diagnosis was paradoxical embolism through a previously undetected atrial septal defect. Suggestions for the evaluation and emergency management of paradoxical embolism are outlined, and the literature is briefly reviewed.
\end{abstract}

Key words: paradoxical embolism; deep venous thrombosis; pulmonary embolism; arterial occlusions; atrial septal defect

\section{RÉSUMÉ}

Le présent article décrit le cas d'un homme âgé de 43 ans atteint d'une embolie paradoxale. Le patient souffrait simultanément d'une thrombose veineuse profonde, d'une embolie pulmonaire et d'occlusions artérielles bilatérales menaçantes pour les membres. Le diagnostic unificateur fut une embolie paradoxale grâce à l'identification d'une communication interauriculaire jusque là non décelée. Les grandes lignes des suggestions pour l'évaluation et la prise en charge d'urgence de l'embolie paradoxale sont offertes et la littérature est brièvement passée en revue.

\section{Introduction}

Paradoxical embolism (PDE) occurs when venous embolic material passes through an intracardiac communication with right-to-left shunt, becoming a systemic arterial embolism. Paradoxical emboli are considered rare events, estimated to represent $2 \%$ of arterial emboli. ${ }^{1}$ However, this condition can have catastrophic outcomes, with a reported early mortality rate of $21 \% .^{2}$ This report describes a 43 -year-old man who presented to the emergency department (ED) with leg pain and was found to have concurrent deep venous thrombosis, pulmonary embolism and acute peripheral arterial embolism. Further investigation revealed a large atrial septal defect, which led to a final diagnosis of PDE.

\section{Case report}

A 43-year-old male construction worker presented to the ED of the Credit Valley Hospital, a community hospital in Mississauga, Ont., with left leg pain and numbness. The patient had been driving to work at $0630 \mathrm{hrs}$ when he experienced acute onset of left calf pain associated with numbness. He returned home, but the pain became so severe that he could not ambulate, and an ambulance was called. The ambulance

From the Emergency Department, Credit Valley Hospital, Mississauga, Ont.

Received: June 3, 2003; final submission: Oct. 22, 2003; accepted: Nov. 3, 2003

This article has been peer reviewed.

Can J Emerg Med 2004;6(1):40-4 
crew arrived at $0656 \mathrm{hrs}$; they noted an initial pulse of 100 beats $/ \mathrm{min}$ and a respiratory rate of 40 breaths $/ \mathrm{min}$. The paramedics attempted but could not obtain an oxygen saturation reading, reporting "fingers too cold." They found equal air entry on auscultation of the chest, and equal peripheral pulses with good bilateral leg movement. The patient denied shortness of breath or chest pain. The primary problem was assessed to be leg pain. The paramedics "coached resps," and transported him to hospital.

On arrival in the ED at $0730 \mathrm{hrs}$, the patient was placed in the intermediate acuity area, but was transferred to the resuscitation area when his oxygen saturation was found to be $70 \%$ on room air. Physical examination at $0755 \mathrm{hrs}$ showed a well developed man who was pale and diaphoretic. Vital signs revealed a blood pressure of 140/99 $\mathrm{mm} \mathrm{Hg}$, pulse of 96 beats/min, respiratory rate of 20 breaths/min, temperature of $36.7^{\circ}$ orally. Oxygen saturation rose to $92 \%$ with the administration of $100 \%$ oxygen. The lungs were clear bilaterally, and cardiac examination was normal. There was no jugular venous distension, calf tenderness or dependent edema. Abdominal examination was unremarkable, and neurologic examination showed symmetric sensory and motor function, with normal reflexes. Closer examination revealed the left leg to be slightly pale and cool compared to the right. Femoral pulses were strong and equal, with no bruits. The right popliteal pulse was normal, but the left was not palpable. There was decreased capillary refill in both feet. A previous health professional had left pen markings over both dorsalis pedis arteries, indicating present pulses, but the emergency physician could not palpate pedal pulses.

Prior medical history revealed a visit to his family doctor 2 days earlier for shortness of breath. His doctor had diagnosed asthma and started him on a beta-agonist/steroid inhaler. The patient stated he had been treated for pneumonia the year previously, but otherwise had been healthy. He denied chest pain, palpitations, cough, sputum production, smoking history, fever or trauma. The patient often worked in a crouched position in the construction industry, and experienced intermittent mild leg pain and swelling in the past, but never felt the need to consult a physician for this. Family history was remarkable only for an uncle who had a myocardial infarction at age 50 .

The initial electrocardiogram (ECG) revealed a sinus tachycardia of 103, with deep T-wave inversions in leads V1 to V5. There was no prior ECG for comparison. The results of a portable chest radiograph were normal. The white blood cell count was $12.4 \times 10^{9} / \mathrm{L}$; hemoglobin, 163 $\mathrm{g} / \mathrm{L}$; glucose, $11.1 \mathrm{mmol} / \mathrm{L}$; fibrinogen, $4.27 \mathrm{~g} / \mathrm{L}$ (normal, $1.10-3.80 \mathrm{~g} / \mathrm{L}$ ), and the quantitative immunolatex D-dimer level was $>4.0 \mathrm{mg} / \mathrm{L}$ (normal range, $0-0.5 \mathrm{mg} / \mathrm{L}$ ). An arterial blood gas on $100 \%$ oxygen revealed marked hypoxia, with $\mathrm{pH}=7.47, P_{\mathrm{O}_{2}}=59, P_{\mathrm{CO}_{2}}=27$ and $\mathrm{HCO}_{3}=19$. Portable Doppler examination confirmed absence of the left popliteal and both dorsalis pedis pulses. At 0840 the patient was taken to the vascular laboratory for arterial and venous studies, which revealed deep venous thrombosis (DVT) of the left leg and arterial occlusions of the left femoral artery and right popliteal artery. At this time, the patient was administered heparin and an emergent vascular surgery consultation was requested.

A transthoracic echocardiogram in the ED showed no evidence of intracardiac thrombus. Left ventricular function was normal, but the right ventricle was dilated and hypokinetic, consistent with pulmonary embolism. No evidence of shunt was seen on this examination. The vascular surgeon requested magnetic resonance angiography, which revealed occlusion of the left superficial femoral and right popliteal arteries (Fig. 1). Subsequent computerized tomography angiograms of the chest revealed large bilateral intralobar pulmonary emboli (Fig. 2). The diagnosis at this time was bilateral arterial thromboses, left leg deep vein thrombosis and extensive pulmonary embolism.

Intra-arterial thrombolysis was attempted, but discontinued after 12 hours because of localized bleeding. Repeat angiography revealed good flow on the right but poor cir-

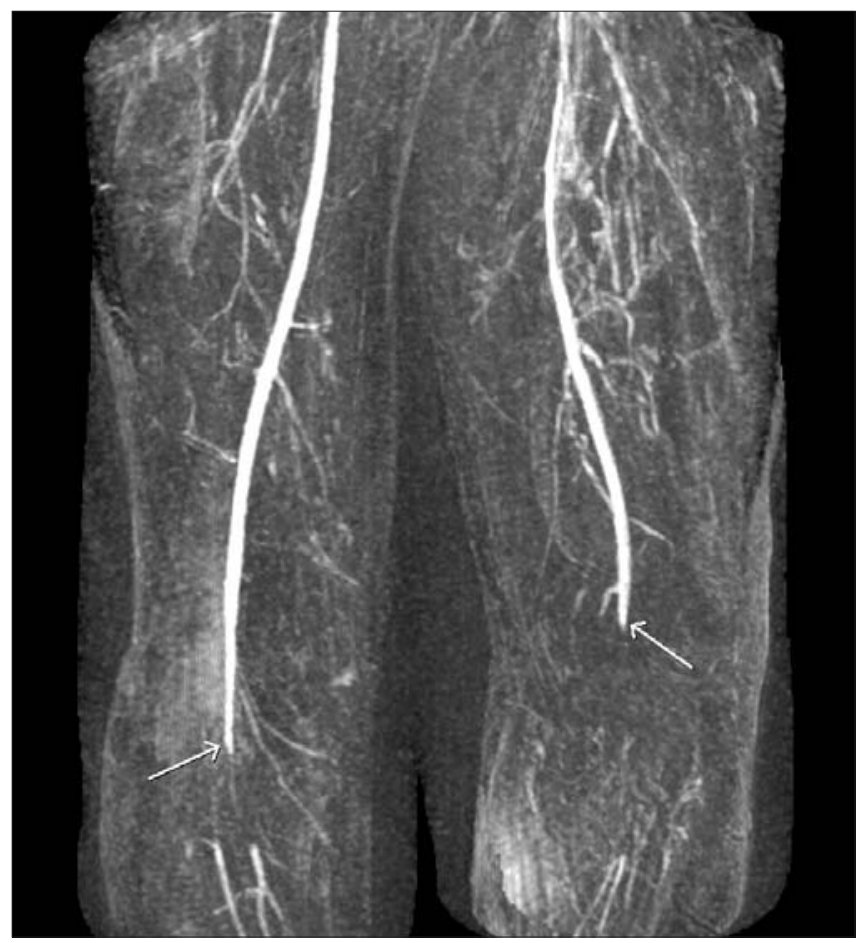

Fig. 1. Arteriogram demonstrating bilateral filling defects in the right popliteal and left superficial femoral arteries consistent with embolic occlusions. 
culation to the left leg below the popliteal artery. This necessitated surgical left-leg thrombectomy, which was complicated by a compartment syndrome requiring fasciotomy.

A transesophageal echocardiogram performed after admission revealed a large, previously unrecognized atrial septal defect (ASD) with bi-directional flow across the defect, and a very small ventricular septal defect. Thrombophilia work-up revealed that he was a heterozygote for factor V Leiden as well as prothrombin mutation, indicating predisposition toward a hypercoagulable state. Abdominal and pelvic ultrasound showed no evidence of abdominal masses or neoplastic disease.

The patient's oxygenation improved on heparin, and leg perfusion was adequate after thrombolysis and thrombectomy. Oral warfarin therapy was initiated, and he was discharged 26 days later with full ambulation. He underwent successful percutaneous device closure of the ASD several months later, and is now doing well on warfarin maintenance.

\section{Discussion}

A focused examination in the clinical setting of suspected pulmonary embolism should include examination of the lower extremity vasculature including pulses, colour and capillary refill. This takes seconds to perform, and can rapidly direct physicians toward identification of PDE, a rare life- and limb-threatening condition. The early physical findings of acute arterial occlusion may be subtle and can be easily missed. If PDE is suspected, arterial and venous ultrasound of the lower extremities will expedite the diagnosis.

In this case, the presenting symptoms of leg pain and dyspnea could have led to a diagnosis of DVT with pul-

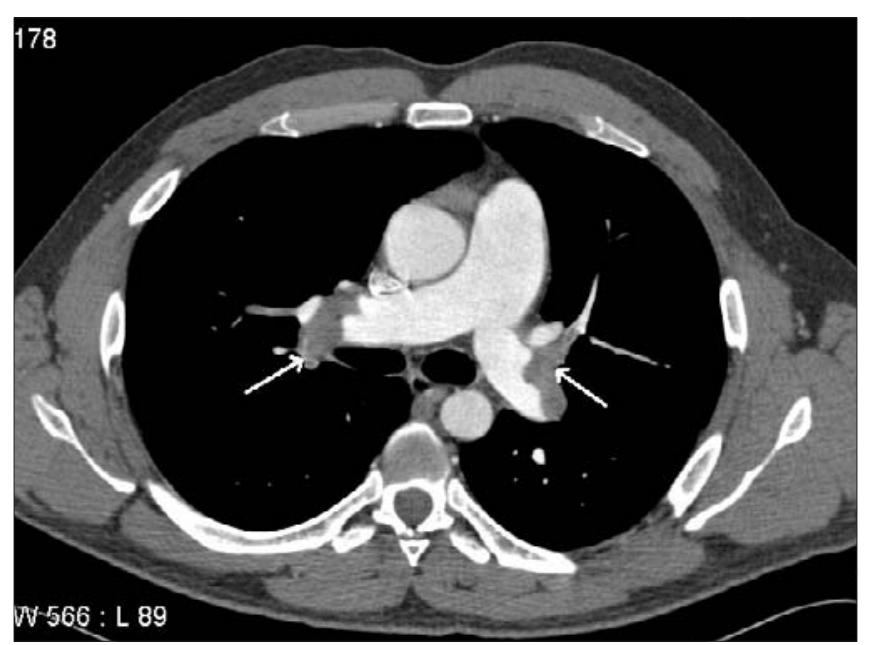

Fig. 2. Pulmonary computed tomography angiogram demonstrating large bilateral intralobar pulmonary emboli. monary embolism, followed by treatment with anticoagulation alone. But failure to recognize PDE is potentially disastrous, leaving patients at risk of limb ischemia, amputation and potentially lethal future embolic events across an unrecognized ASD; therefore, when PDE is suspected, anticoagulation alone is inadequate and emergent surgical consultation is indicated. In this case, immediate diagnosis was crucial to the initiation of therapy to salvage this patient's leg. In addition, investigation of the lower limb symptoms led to the finding of contralateral thrombosis and to the search for the ASD, which connected the systemic arterial emboli to the venous thrombosis.

Adults may have congenital cardiac anomalies and clotting disorders that go unrecognized for decades, then suffer acute life- and limb-threatening complications. Many patients with ASD can present, as this patient did, without an audible cardiac murmur because of the low pressure gradient across the ASD. As in this case, transthoracic echocardiography may be unrevealing. Transesophageal echocardiography is more sensitive in detecting occult intracardiac defects, and may be preferable in suspected cases of PDE.

\section{Literature review}

First described by Cohnheim in $1877,{ }^{3}$ PDE involves the passage of venous embolic material through a right-to-left intracardiac shunt into the arterial circulation. Postmortem cases were reported in the literature until 1930, when the first case of PDE was diagnosed during life. ${ }^{4}$ Echocardiography has simplified the diagnosis of PDE, but PDE still remains an under-recognized entity, usually identified postmortem. ${ }^{5,6}$ The clinical signs of PDE are often subtle and easily overlooked; its recognition depends mainly on clinical awareness. ${ }^{7}$ Presumptive diagnosis is based on the clinical triad of 1) systemic arterial embolism in the absence of left-sided cardiac or proximal arterial source, 2) venous thromboembolism (DVT or pulmonary embolism), and 3) an intracardiac defect with right-to-left shunting. ${ }^{8}$ The definitive diagnosis is made at autopsy, or when thrombus is seen crossing a right-to-left shunt in the face of an arterial embolus.

Usual sites of embolization are the extremities (49\%), the brain (37\%) and, less frequently, the coronary, renal or splenic arteries. ${ }^{9}$ Typical presentations include cryptogenic stroke, brain abscess and decompression sickness in underwater divers. ${ }^{10}$ The onset of symptoms during a Valsalva manoeuvre is suggestive of PDE. ${ }^{11}$

Contrast transthoracic or transesophageal echocardiography during and after provocative manoeuvres, such as Valsalva or cough, have been recommended to definitively di- 
agnose PDE. ${ }^{12}$ One should always specifically mention the possibility of PDE when ordering an echocardiogram to identify the source of embolus so that appropriate Valsalva, cough and contrast manoeuvres may be performed. Transesophageal echocardiography is more sensitive than transthoracic echocardiograpy, with better image definition resulting from proximity to the septum, and the ability to use a higher frequency transducer because less tissue must be traversed by the ultrasound beam., ${ }^{2,13}$ The superiority of transesophageal echocardiography is illustrated by its diagnostic performance in patients with patent foramen ovale, where transesophageal echocardiography is $100 \%$ sensitive, $92 \%$ specific and $97 \%$ accurate, and transthoracic echocardiography is $63 \%$ sensitive, $100 \%$ specific and $78 \%$ accurate. ${ }^{14}$ More recently, contrast transcranial Doppler ultrasonography has been used to identify rightto-left intra-cardiac shunting ${ }^{15,16}$ by detecting rapid appearance of contrast medium in the middle cerebral artery after venous injection.

Several intracardiac defects have been associated with PDE. The most common, patent foramen ovale, occurs in up to $27.3 \%$ of the general population (based on data from one large autopsy series). ${ }^{17}$ Atrial septal defect, pulmonary arteriovenous malformation, ventricular septal defect, Ebstein's anomaly and patent truncus arteriosus are also associated with PDE..$^{5,8,18}$ The physiologic left-to-right atrial pressure gradient promotes left-to-right shunting across a cardiac defect; therefore, under normal conditions, such a defect does not cause PDE. However, when right atrial pressures increase and exceed left atrial pressures, right-toleft shunting occurs. Pulmonary embolism causes acute right atrial pressure elevation, and has been identified in at least $60 \%$ of diagnosed PDE. ${ }^{919}$ Other predisposing conditions include Valsalva manoeuvre, cough, and chronic lung disease with pulmonary hypertension. ${ }^{9,20}$

The optimal management of PDE remains controversial. ${ }^{10}$ The heterogeneity and complexity of these patients, together with their acuity of illness, makes management highly individualized. ${ }^{5,21}$ The most cost-effective diagnostic and treatment strategy is yet to be determined, and the optimal approach will depend on patient characteristics and available hospital resources and expertise. ${ }^{11}$ Most authors agree that systemic anticoagulation should be initiated immediately on the diagnosis of arterial emboli, unless there are major contraindications. ${ }^{6,9,11,19,22}$ Vena cava filter insertion is recommended when anticoagulation is contraindicated, ${ }^{23}$ although these filters do not protect against emboli smaller than $3 \mathrm{~mm} .{ }^{24}$ Thrombolytic therapy is advised for the management of hemodynamically significant pulmonary embolism, ${ }^{19}$ and intra-arterial thrombolysis or surgical em- bolectomy should be considered in the treatment of limbthreatening ischemia. ${ }^{19}$ In the rare case of an impending PDE (e.g., thrombus straddling an intracardiac defect on echocardiography), intracardiac embolectomy and surgical correction of the intracardiac defect has been attempted successfully, ${ }^{25}$ as has urgent pulmonary embolectomy. ${ }^{26}$

Recommended therapies to prevent recurrent arterial embolism after PDE include antiplatelet agents, systemic anticoagulation, and percutaneous or open surgical closure of the intracardiac defect. ${ }^{21,27-29}$ Antiplatelet and antithrombotic therapy are simple and relatively inexpensive but have important disadvantages, including the need for prolonged or life-long treatment, the risk of major bleeding, and the possibility of significant drug interactions. Surgical closure of the intracardiac defect is invasive and expensive, with the known risks of open heart surgery. Percutaneous closure (with a variety of devices) appears to be safer and less expensive than open surgical methods, and has been used with increasing frequency during the last few years. ${ }^{10,12,30,31}$ These newer procedures have potential complications, including device embolization, cardiac tamponade and thrombus formation on the device surface. Unfortunately, because of the rarity of PDE, there have been no large prospective studies comparing medical treatment, surgery and percutaneous closure of intracardiac defects for the prevention of future PDE.

\section{Conclusion}

In patients with arterial embolism, the origin of the embolus should be identified. PDE, a rare but important condition, should be suspected whenever unexplained arterial occlusion occurs, particularly in younger patients and those with concurrent DVT or pulmonary embolism. Current recommendations for the evaluation and treatment of PDE have been outlined. Increased awareness of PDE will lead to timely emergency intervention, averting potentially catastrophic outcomes.

Competing interests: None declared.

\section{References}

1. Mirarchi FL, Hecker J, Kramer CM. Pulmonary embolism complicated by patent foramen ovale and paradoxical embolization. J Emerg Med 2000;19(1)27-30.

2. Aboyans V, Lacroix P, Ostyn E, Cornu E, Laskar M. Diagnosis and management of entrapped embolus through a patent foramen ovale. Eur J Cardiothorac Surg 1998;14(6):624-8.

3. Cohnheim J. Thrombose und embolie. Vorl Allg Pathol 1877; 1:143-4.

4. Thompson T, Evans W. Paradoxical embolism. QJM1930;23: 135-50. 
5. Ward R, Jones D, Haponik EF. Paradoxical embolism: an underrecognized problem. Chest 1995;108(2):549-58.

6. AbuRahma AF, Lucente FC, Boland JP. Paradoxical embolism: an underestimated entity. A plea for comprehensive work-up. J Cardiovasc Surg 1990;31:685-92.

7. Georgopoulos SE, Chronopoulos A, Dervisis KI, Arvanitis DP. Paradoxical embolism: an old but, paradoxically, underestimated problem. J Cardiovasc Surg 2001;42(5):675-7.

8. Johnson BI. Paradoxical embolism. J Clin Pathol 1951;4:316-32.

9. Loscalzo J. Paradoxical embolism: clinical presentation, diagnostic strategies, and therapeutic options. Am Heart J 1986;112:141-5.

10. Martin F, Sanchez PL, Doherty E, Colon-Hernandez PJ, Delgado G, Inglessis I, et al. Percutaneous transcatheter closure of patent foramen ovale in patients with paradoxical embolism. Circulation 2002;106(9):1121-6.

11. Meacham RR 3rd, Headley S, Bronze MS, Lewis JB, Rester MM. Impending paradoxical embolism. Arch Intern Med 1998; 158(5):438-48.

12. Cheng TO. Paradoxical embolism: diagnosis and management. J Emerg Med 2001;20(4):416-8.

13. Nacht A, Kronzon I. Intracardiac shunts. Crit Care Clin 1996; 12(2):295-319.

14. Chen W, Kuan P, Lien W, Lin F. Detection of patent foramen ovale by contrast transesophageal echocardiography. Chest 1992; 101:1515-20.

15. Jauss M, Kaps M, Keberle M, Haberbosch W, Dorndorf W. A comparison of transesophageal echocardiography and transcranial Doppler sonography with contrast medium for detection of patent foramen ovale. Stroke 1994;25:1265-7.

16. Job FP, Ringelstein EB, Grafen Y, Flachskampf FA, Doherty C, Stockmanns A, et al. Comparison of transcranial contrast Doppler sonography and transesophageal contrast echocardiography for the detection of patent forament ovale in young stroke patients. Am J Cardiol 1994;74:381-4.

17. Hagen PT, Scholz DG, Edwards WD. Incidence and size of patent foramen ovale during the first 10 decades of life: an autopsy study of 965 normal hearts. Mayo Clin Proc 1984;59:12-20.

18. Gazzaniga AB, Dalen JE. Paradoxical embolism: its pathophysiology and clinical recognition. Ann Surg 1970;171:137-42.

19. Leonard RCF, Neville E, Hall RJC. Paradoxical embolism: a review of cases diagnosed during life. Eur Heart J 1982;3:352-70.

20. Meister SG, Grossman W, Dexter L, Dalen JE. Paradoxical embolism: diagnosis during life. Am J Med 1972;53:292-8.

21. Travis JA, Fuller SB, Ligush J, Plonk GW, Geary RL, Hansen KJ. Diagnosis and treatment of paradoxical embolus. J Vasc Surg 2001;34(5):860-5.

22. Wongpraparut N, Zamen M, Langan N, Jacobs L, Kotler M, Owen AN. Paradoxical embolism. Echocardiography 2002; 19(1):77-8.

23. Greenfield LJ, Proctor MC. Twenty-year clinical experience with the Greenfield filter. Cardiovasc Surg 1995;3:199-205.

24. Chaikof EL, Campbell BE, Smith RB. Paradoxical embolism and acute arterial occlusion: rare or unsuspected? J Vasc Surg 1994;20:377-84.

25. Ngaage DL, Bhamra GS, Gaynor S, Nair UR. Saved by the bell: early surgical treatment for cardiosystemic thromboembolism. J Thorac Surg 2002;123(5):1010-1.

26. Van Dantzig JM, Cherieux EC, Snoep G, Prenger KB. Impending paradoxical embolus: clinical imaging and successful surgical treatment. Int J Card Imaging 1998;14(3):167-70.
27. Bogousslavsky J, Garazi S, Jeanrenaud X, Aebischer N, Van Melle G. Stroke recurrence in patients with patent foramen ovale: the Lausanne Study. Neurology 1996;46:1301-5.

28. Mas JL, Zuber M. Recurrent cerebrovascular events in patients with patent foramen ovale, atrial septal aneurysm, or both and cryptogenic stroke or transient ischemic attack. Am Heart J 1995; 130:1083-8.

29. Nendaz M, Sarasin FP, Bogousslavsky J. How to prevent stroke recurrence in patients with patent foramen ovale: anticoagulants, antiaggregants, foramen closure, or nothing? Eur Neurol 1997;37:199-204.

30. Hung J, Landzberg MJ, Jenkins KJ, King ME, Lock JE, Palaciosis IF, et al. Closure of patent foramen ovale for paradoxical emboli: intermediate-term risk of recurrent neurological events following transcatheter device placement. J Am Coll Cardiol 2000;35(5):1311-6.

31. Bruch L, Parsi A, Grad MO, Rux S, Burmeister T, Krebs H, et al. Transcatheter closure of interatrial communications for secondary prevention of paradoxical embolism: single-center experience. Circulation 2002;105(24):2845-8.

Correspondence to: Dr. Christine E. Tang, Credit Valley Hospital, 2200 Eglinton Ave. West, Mississauga ON L5M 2N1; cetang@sympatico.ca
BIS Inc.

$1 / 4$ page b/w

Repeat of November 2003, page 399 